\title{
Is it time for greater patient involvement to enhance transitional medication safety?
}

\author{
Tamasine C Grimes
}

\section{Correspondence to}

Dr Tamasine C Grimes, School of Pharmacy and Pharmaceutical Sciences, Trinity College Dublin, Dublin 2, Ireland; tagrimes@tcd.ie

Accepted 14 August 2021

\section{Linked}

- http://dx.doi.org/10.1136/ bmjqs-2020-012709

\section{Check for updates}

(C) Author(s) (or their employer(s)) 2021. No commercial re-use. See rights and permissions. Published by BMJ.

To cite: Grimes TC. BMJ Qual Saf Epub ahead of print: [please include Day Month Year]. doi:10.1136/ bmjqs-2021-014116
In this issue of BMJ Quality \& Safety, Schnipper et al report the effects of a refined evidence-based toolkit and mentored implementation of a complex medication reconciliation intervention, 'MARQUIS2', at 18 North American hospitals. ${ }^{1}$ This pragmatic quality improvement study used interrupted time series analysis to quantify the effects of implementation on medication discrepancy rates relative to baseline trends. The MARQUIS2 toolkit was developed by refining the earlier MARQUIS1 toolkit, shown to be associated with a reduction in medication discrepancies but with inconsistent improvement among the five study sites. ${ }^{2}$ In brief, subsequent changes made to MARQUIS1 included (1) addition of simulated cases as training materials and to assess competency in taking a best possible medication history (BPMH), (2) greater use of pharmacy technicians to take BPMHs, (3) provision of advocacy aids, for example, return-on-investment calculators, to promote resourcing of medication reconciliation, (4) changes to electronic health records' medication reconciliation functionality and (5) revision of patient/caregiver discharge education materials. The MARQUIS2 toolkit employed both system-level interventions, such as training staff to take a $\mathrm{BPMH}$, and patient-level interventions, such as performing a BPMH. The study reported an increase in the number of system-level interventions adopted per site, an increase in the proportion of patients receiving patient-level interventions over time and a decrease in discrepancies per month over baseline trends. The authors identified that delivery of system-level interventions alone was not associated with decreased discrepancy rates, while receipt of patient-level interventions alone was. The MARQUIS2 study findings therefore provide muchneeded insights into the implementation of a medication reconciliation focused intervention across multiple sites. These findings also raise three important questions: are patients currently involved in managing their own medication safety at care transitions, should they be and how or when might this be done?

There is evidence that the patient often has a passive and inexplicit role in transitional patient safety in general ${ }^{34}$ and transitional medication safety in particular, ${ }^{56}$ despite frequently wanting greater involvement. Patients have been shown to be effective and willing actors in supporting their own transitional medication safety. ${ }^{7}$ For example, Fylan et al demonstrated that patients are an important source of system resilience following hospital discharge; they anticipate and identify medication errors, take preventative and corrective action to manage error and contribute to information management at various points. ${ }^{7}$ Additionally, the extent of the patient's involvement in their own transitional safety is modifiable and influenced by their beliefs and perception of consequences $^{3}$; patients participate actively in handovers of care when they feel a need for involvement to ensure care continuity but are less active when they believe that their contribution is unnecessary or not appreciated. ${ }^{3}$ Such patient-led activities constitute medication work, a type of patient work that is an increasingly valued aspect of transitional medication safety. ${ }^{89}$ This is relevant to medication reconciliation because hospitalisation is associated with an increasing burden of potentially inappropriate prescribing, increasing medication regimen complexity and deprescribing of long-term medication. ${ }^{10}$ Holden and Abebe argue that 
medication changes, whether the addition of new medications or the deprescribing of established medications, are vulnerable periods for patients and add to their medication work burden. ${ }^{12}$ Therefore, the patient's medication work burden at periods around care transitions merits attention. Although evidence suggests that patients currently have limited involvement in their own transitional medication safety, it also suggests that they ought to be supported to be more involved.

Patient activation refers to a patient's knowledge, skills and confidence in self-managing their own health. ${ }^{13}$ Patients who are more activated have better health outcomes and experience better care than those who are less activated, while those who are less activated are more likely to have unmet medical needs and to experience delays in care. ${ }^{13}$ Patient education and counselling, and patient follow-up postdischarge, have been identified as important patient-level interventions at care transitions contributing to reduced medication discrepancies ${ }^{14} 15$ and reduced healthcare utilisation. ${ }^{16} 17$ However, these activities represent behaviours delivered by professionals to patient/caregiver recipients and the extent to which they support patient activation or contribute to the patient's medication work burden is unknown. Patient ergonomics, a field exploring the science and engineering of patient work, might therefore provide insights into opportunities to modify and nurture patient activation and opportunities for patient involvement in medication reconciliation. ${ }^{18}$

The MARQUIS2 patient-level interventions, such as health coaching and patient counselling, ${ }^{1}$ were all delivered during the patient's acute hospital stay. The timing of intervention delivery warrants consideration, because a qualitative study of the hospital discharge process suggests that patients are suboptimally involved in discharge preparation and healthcare providers attempt to engage them at times when they are not receptive to this involvement, for example, on the day of discharge when patients may be pre-occupied with making preparations for returning home. ${ }^{6}$ Information provision and patient education should ideally be aligned with the patient's or caregiver's capacity to receive and engage with the information. ${ }^{9}$ It is possible that attempts to prepare people to be involved in managing their own medication safety at care transitions might be more effective if undertaken while the person is living well with chronic conditions in their own home rather than when they are acutely unwell and hospitalised. A systematic review of measurement tools in transitional patient safety identified several tools examining the patient's perceived preparedness for hospital discharge, but none to assess this for hospital admission. ${ }^{19}$ Emergency hospital admission of community-dwelling adults is to some extent predictable, with polypharmacy as a key predictor. ${ }^{20}$ Therefore, future research could explore ways to involve patients in preparing for their own future care transitions before an emergency occurs.

By its nature, medication safety at care transitions spans boundaries; it requires management of information about multiple patient interactions distributed across multiple systems, spaces and timepoints, as described above and depicted in figure 1. A work system is a construct of the interacting sociotechnical structural elements, such as people, tasks, tools and technologies, organisations and environments, of a body of work. ${ }^{8}$ The MARQUIS2 study explored medication reconciliation within the acute hospital work system. ${ }^{1}$ Calls have been made for a transitional medication safety focus that extends beyond any individual work system, such as the hospital work system or the primary care work system, because the patient's medication management journey is distributed across time and space and therefore focusing on any one system is insufficient. ${ }^{891819}$ To fully understand the patient journey and what leads to positive and negative consequences for transitional medication safety, future research could take a systems-based perspective across all relevant and interacting work systems. ${ }^{9}$ The Systems Engineering Initiative for Patient Safety (SEIPS) model provides a framework for integrating human factors/ ergonomics in healthcare quality and patient safety improvement. ${ }^{21}$ A previous study of distributed healthcare tasks exemplifies application of the SEIPS model to medication management across the hospitalto-home transition. ${ }^{22}$ It demonstrates that a systemsbased exploration can uncover a wide range of system boundary types including those between organisations, over time and professional-to-non-professional boundaries that would not have been observed with a narrower focus on a single work system. It also usefully uncovered details about the patient's medication work system and its interaction with other work systems. The third iteration of the SEIPS model, SEIPS 3.0, calls for a focus on the patient's and caregiver's journey over space and time as they interact with multiple elements and navigate the borders between them. ${ }^{21}$ SEIPS 3.0 therefore provides a helpful way to conduct a systems-based exploration of transitional medication safety that requires patient and public involvement (PPI), with an emphasis on patient ergonomics and the interactions between the patient's medication work system and other relevant work systems.

The MARQUIS2 study sought to engage patient and family representatives in intervention development and evaluation by inviting them to contribute to developing discharge education and counselling materials and to be involved in all aspects of the research study. ${ }^{1}$ Additionally, community engagement and social marketing to patients as well as clinicians were among the system-level MARQUIS2 stakeholder involvement interventions. These are welcome examples of PPI in medication reconciliation, because there is mounting evidence that PPI enhances the quality, validity and 


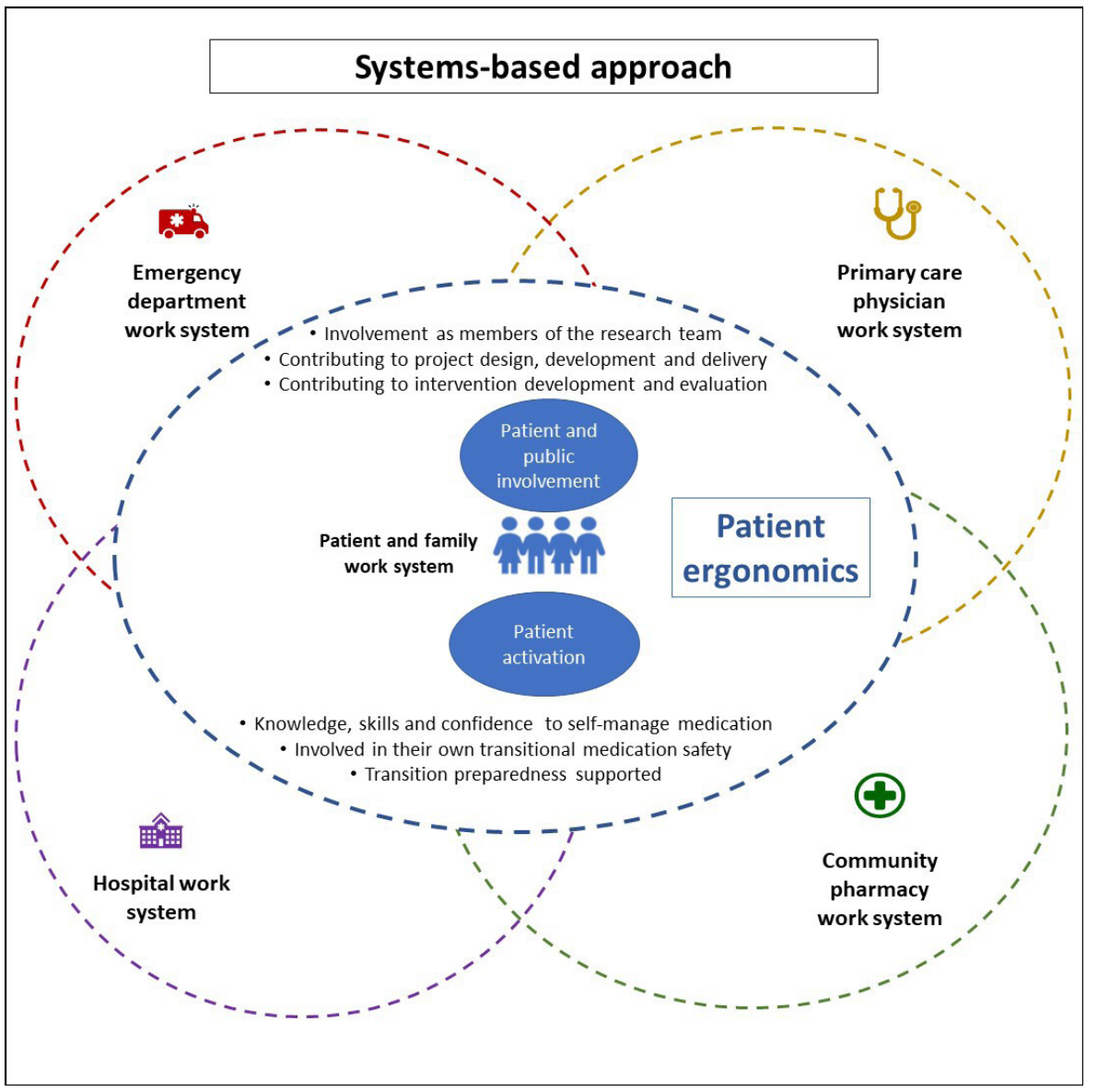

Figure 1 Patient medication work system situated within a system of interacting elements and work systems.

impact of research and service development ${ }^{23}$ and yet PPI in medication reconciliation research is relatively rare and has not been described in systematic reviews examining the topic. ${ }^{14-17}$ Ocloo and Matthews argue for a move to meaningful and democratic inclusion of the relevant healthcare improvement patient population beyond what they described as the more prevalent tokenistic engagement of a narrow selection of PPI contributors. ${ }^{24}$ Although community engagement and social marketing were recommended MARQUIS2 system-level interventions, only 2 and 3 sites, respectively, of the 18 included study sites actually implemented these components with little detail on the nature of the PPI contributors or contributions to the overall research programme. ${ }^{1}$ Information about the facilitators and barriers to the adoption of community engagement and stakeholder involvement at individual study sites would therefore be instructive for those seeking to involve patients and the public in similar healthcare improvements. Articles describing PPI in medication safety research may offer helpful insights into how to conduct and report PPI, such as the types of engagement activities, the stages of the project when engagement might occur, the challenges encountered, the benefits realised and some general tips on supporting collaboration and partnership with patients and the public. ${ }^{2526}$
The report by Schnipper et al on the implementation and evaluation of the MARQUIS2 toolkit provides much-needed evidence to guide others seeking to implement medication reconciliation interventions at scale. ${ }^{1}$ It suggests either that patient-level interventions may be more important than system-level interventions, or that system-level interventions are necessary but not sufficient alone. Future transitional medication safety research could be further enhanced by exploring ways to promote patient involvement and activation in their own care, partnering with patient and caregiver stakeholders as members of the quality improvement and research teams and applying a systems-based exploration across the entire patient journey, inclusive of the patient's medication work system and patient ergonomics.

Twitter Tamasine C Grimes @tagrimes

Funding The authors have not declared a specific grant for this research from any funding agency in the public, commercial or not-for-profit sectors.

Competing interests None declared.

Patient consent for publication Not required.

Provenance and peer review Commissioned; internally peer reviewed.

ORCID ID

Tamasine C Grimes http://orcid.org/0000-0002-7154-3243 


\section{REFERENCES}

1 Schnipper JL, Reyes Nieva H, Mallouk M, et al. Effects of a refined evidence-based toolkit and mentored implementation on medication reconciliation at 18 hospitals: results of the MARQUIS2 study. BMJ Qual Saf 2021. doi:10.1136/ bmjqs-2020-012709. [Epub ahead of print: 29 Apr 2021].

2 Schnipper JL, Mixon A, Stein J, et al. Effects of a multifaceted medication reconciliation quality improvement intervention on patient safety: final results of the Marquis study. BMJ Qual Saf 2018;27:954-64.

3 Flink M, Öhlén G, Hansagi H, et al. Beliefs and experiences can influence patient participation in handover between primary and secondary care--a qualitative study of patient perspectives. BMJ Qual Saf 2012;21(Suppl 1):i76-83.

4 Poldervaart JM, van Melle MA, Reijnders LJ, et al. Transitional safety incidents as reported by patients and healthcare professionals in the Netherlands: a descriptive study. Eur J Gen Pract 2019;25:77-84.

5 Garfield S, Jheeta S, Husson F, et al. The role of hospital inpatients in supporting medication safety: a qualitative study. PLoS One 2016;11:e0153721.

6 Rognan SE, Kälvemark Sporrong S, Bengtsson K, et al . Discharge processes and medicines communication from the patient perspective: a qualitative study at an internal medicines ward in Norway. Health Expect 2021;24:892-904.

7 Fylan B, Armitage G, Naylor D, et al. A qualitative study of patient involvement in medicines management after hospital discharge: an under-recognised source of systems resilience. BMJ Qual Saf 2018;27:539-46.

8 Werner NE, Ponnala S, Doutcheva N, et al. Human factors/ ergonomics work system analysis of patient work: state of the science and future directions. Int J Qual Health Care 2021;33:60-71.

9 Werner NE, Rutkowski RA, Arbaje AI. The Patient ergonomics approach to care transitions: care transitions as a patient journey. In: Holden RJ, Valdez RS, eds. The patient factor. UK: CRC Press, 2021: 29-47.

10 Elliott RA, O'Callaghan CJ. Impact of hospitalisation on the complexity of older patients' medication regimens and potential for regimen simplification. J Pharm Pract Res 2011;41:21-5.

11 Pérez T, Moriarty F, Wallace E, et al. Prevalence of potentially inappropriate prescribing in older people in primary care and its association with hospital admission: longitudinal study. BMJ 2018;363:k4524.

12 Holden RJ, Abebe E. Medication transitions: vulnerable periods of change in need of human factors and ergonomics. Appl Ergon 2021;90:103279.
13 Chieng M, Southwell T, Shand G, et al. How do hospitals help patients prepare for and participate in outpatient clinics? Intern Med J 2021. doi:10.1111/imj.15248. [Epub ahead of print: 01 Mar 2021].

14 Mueller SK, Sponsler KC, Kripalani S, et al. Hospital-based medication reconciliation practices: a systematic review. Arch Intern Med 2012;172:1057-69.

15 Redmond P, Grimes TC, McDonnell R, et al. Impact of medication reconciliation for improving transitions of care. Cochrane Database Syst Rev 2018;8:CD010791.

16 Kwan JL, Lo L, Sampson M, et al. Medication reconciliation during transitions of care as a patient safety strategy: a systematic review. Ann Intern Med 2013;158:397-403.

17 Mekonnen AB, McLachlan AJ, Brien J-AE. Effectiveness of pharmacist-led medication reconciliation programmes on clinical outcomes at hospital transitions: a systematic review and meta-analysis. BMJ Open 2016;6:e010003.

18 Holden RJ, Valdez RS. Patient ergonomics: The science (and engineering) of patient work. In: Holden RJ, Valdez RS, eds. The patient factor. UK: CRC Press, 2021: 3-18.

19 van Melle MA, van Stel HF, Poldervaart JM, et al. Measurement tools and outcome measures used in transitional patient safety; a systematic review. PLoS One 2018;13:e0197312.

20 Wallace E, Stuart E, Vaughan N, et al. Risk prediction models to predict emergency hospital admission in community-dwelling adults: a systematic review. Med Care 2014;52:751-65.

21 Carayon P, Wooldridge A, Hoonakker P, et al. SEIPS 3.0: Human-centered design of the patient journey for patient safety. Appl Ergon 2020;84:103033.

22 Werner NE, Malkana S, Gurses AP, et al. Toward a processlevel view of distributed healthcare tasks: medication management as a case study. Appl Ergon 2017;65:255-68.

23 Wicks P, Richards T, Denegri S, et al. Patients' roles and rights in research. BMJ 2018;362:k3193.

24 Ocloo J, Matthews R. From tokenism to empowerment: progressing patient and public involvement in healthcare improvement. BMJ Qual Saf 2016;25:626-32.

25 Giles SJ, Lewis PJ, Phipps DL, et al. Capturing patients' perspectives on medication safety: the development of a patient-centered medication safety framework. J Patient Saf 2020;16:e324-39.

26 Tomlinson J, Medlinskiene K, Cheong V-L, et al. Patient and public involvement in designing and conducting doctoral research: the whys and the Hows. Res Involv Engagem $2019 ; 5: 23$. 